\author{
\& Governance
}

\title{
Organizational and Individual Determinants of Evidence Use by Managers in Public Human Service Organizations
}

\section{Bowen McBeath, Monica Pérez Jolles, Sarah Carnochan \& Michael J. Austin}

To cite this article: Bowen McBeath, Monica Pérez Jolles, Sarah Carnochan \& Michael J. Austin (2015) Organizational and Individual Determinants of Evidence Use by Managers in Public Human Service Organizations, Human Service Organizations: Management, Leadership \& Governance, 39:4, 267-289, DOI: 10.1080/23303131.2015.1044588

To link to this article: http://dx.doi.org/10.1080/23303131.2015.1044588
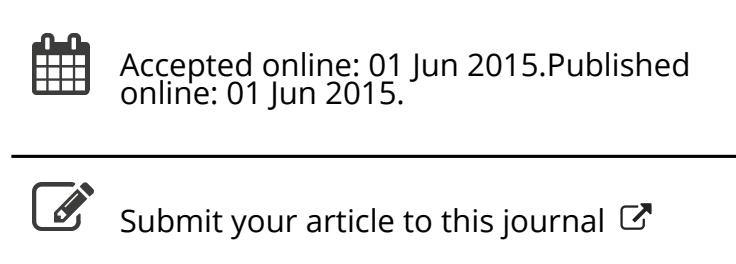

Llll Article views: 33

$\frac{\bar{Q} \text { View related articles } \square}{\square_{\text {cossnatk }} \text { View Crossmark data } \square}$




\title{
Organizational and Individual Determinants of Evidence Use by Managers in Public Human Service Organizations
}

\author{
Bowen McBeath \\ School of Social Work and Hatfield School of Government (Division of Public Administration), \\ Portland State University, Portland, Oregon, USA \\ Monica Pérez Jolles \\ Gillings School of Global Public Health, Cecil G. Sheps Center for Health Services Research, \\ University of North Carolina-Chapel Hill, Chapel Hill, North Carolina, USA \\ Sarah Carnochan and Michael J. Austin \\ Mack Center for Nonprofit and Public Sector Management in the Human Services, School of \\ Social Welfare, University of California-Berkeley, Berkeley, California, USA
}

\begin{abstract}
Promoting the use of evidence by managers is a strategy for enhancing effectiveness in human service organizations, and for responding to the demands of performance management. This study addresses two multipart questions. First, what levels of managerial evidence use exist in public human service organizations and for what purposes is this evidence used? Second, what organizational factors and individual attitudinal characteristics are associated with different levels of evidence use? Based on survey data from a sample of administrators, middle managers, and supervisors in 11 county public human service organizations located in the San Francisco Bay Area, we find that managers are engaged in evidence use at moderate levels. They are most engaged in reviewing agency reports, searching for research literature and other evidence, and using online resources to identify promising practices. Evidence use is found to be positively associated with having access to performance measurement systems, being an administrator, and being innovation minded and responsive to organizational change. Our findings suggest that evidence use by human service managers may be contingent on organizational resources, organizational role, and individual attitudes. These results underscore the importance of training human service managers in evidence-informed practice in order to promote agencywide knowledge utilization and organizational effectiveness.
\end{abstract}

Keywords: leadership and organizational change, management, workforce/workplace issues in human service organizations

Human service organizations seeking to enhance the evidentiary basis of their services and programs may employ a number of different strategies. At an organizational level, they may engage

Correspondence should be addressed to Bowen McBeath, School of Social Work and Hatfield School of Government, Portland State University, P.O. Box 751, Portland, OR 97201, USA. E-mail: mcbeath@pdx.edu 
in evidence-based management, through which agency leaders make strategic decisions aided by review of available statistics and other organizational data, external research literature, and best practice models (Heinrich, 2007; McDaniel \& Lanham, 2009). Managers may also invest in performance measurement via the development and systematic use of data dashboards that track important organizational and programmatic indicators (Carnochan, Samples, Myers, \& Austin, 2013; Hatry, 2007). At a service program level, administrators may select, implement, and administer evidencebased practices and other manualized evidence-supported treatments (Barth et al., 2012). And at a practitioner level, organizations may seek to cultivate evidence-informed practice, defined as the conscientious integration of available clinical and agency information, client preferences and feedback, practitioner expertise and experience, and the best available research evidence (Gambrill, 2012). Whether at the practitioner, managerial, or organizational level, these strategies direct attention to the process of collecting, using, and disseminating evidence, defined as knowledge that has been gathered systematically and found to be credible (Nutley, Walter, \& Davies, 2003, 2007).

Managerial efforts to integrate research evidence into human service programing and frontline practice are increasingly required by federal agencies and policy makers interested in promoting the accountable and effective use of public funds (U.S. General Accountability Office, 2013). Beyond the focus on improved service quality, these external pressures for evidence use also support a basic commitment to knowledge development, dissemination, and utilization in public services (Nutley et al., 2007). Finally, current pressures to integrate research throughout human service organizations reflect a growing awareness that evidence use at all levels can be difficult to sustain, even when it is required (McBeath \& Austin, in press). For example, Horwitz and colleagues (2014) found that very few public child welfare organizations use any evidence-based practices despite growing demands to do so. Similarly, studies over the past 2 decades have demonstrated that human service practitioners do not use research evidence consistently (Rosen, 1994; Parrish \& Rubin, 2011, 2012).

The current paper focuses on the extent to which managers of public human service organizations engage with different types of evidence to enhance organizational and service delivery outcomes. These types of evidence can include research external to the organization, such as peer-reviewed scholarship and national and local research reports; evidence can also be situated internally to the organization, including agency data, client case records, organizational surveys and other research, and informal evidence gathered through dialogue with staff colleagues and clients (Epstein, 2010). A systematic review of managerial performance information use noted the need for greater attention to how managers use these varied (and often nonquantitative and nonsurvey) evidence bases (Kroll, 2014).

This study addresses two multipart questions. First, what levels of managerial evidence use exist in public human service organizations, and for what ends is this evidence used? If evidence use in human service settings requires special supports and investment to integrate effectively into practice, then it is reasonable to expect that practitioners seeking to access and use evidence do so purposefully and with some expectation of benefit for their clients, themselves, and/or the organization (Nutley et al., 2003, 2007). For example, managerial engagement with evidence can support the identification of promising practices, help answer researchable questions, identify service and program improvement strategies, and clarify client and agency needs. A full understanding of evidence use should consider the extent to which managers at different organizational levels are engaged in evidence use for these instrumental purposes. The current study provides the first systematic examination of managerial evidence use in public human service organizations.

The second question seeks to identify those human service managers who use evidence more than others, and the organizational factors and individual characteristics that are associated with their efforts. Practitioners may be more likely to engage in evidence use in organizational settings characterized by a culture of learning, where evidence use is mandated or incentivized or where there exist cross-agency learning networks (Moynihan \& Lavertu, 2012; Palinkas et al., 2011). Practitioners are also likely to use evidence if they are given time to explore research, discretion 
and training to engage with diverse types of evidence, and access to external and internal evidence (Doran et al., 2012; Gray, Joy, Plath, \& Webb, 2013). These studies imply that managerial evidence use requires dedicated resources and organizational commitment to be sustained effectively (Austin, Dal Santo, \& Lee, 2012). As a result, this question supports the identification of promising approaches to promote the development of evidence-informed human service managers.

To examine both of these questions, we analyze quantitative survey data on practitioner evidence use from a diverse sample of senior to junior managers - including administrators, middle managers, and supervisors - employed in 11 county (public) human service organizations located in the San Francisco Bay Area. Our survey focused on evidence-informed practice in relation to human service organizational practice and included a measure of evidence use that differentiates conceptually between practitioner evidence use, engagement in agency-based research, and research-focused collaboration with internal stakeholders (e.g., clients) and external researchers. Before reviewing our methodology, we first situate our study in the literature on practitioner evidence use and evidence-informed practice.

\section{UNDERSTANDING EVIDENCE USE IN HUMAN SERVICE ORGANIZATIONAL CONTEXTS}

Managerial evidence use can be understood in relation to the broader context of evidence-based practice in the health and human service sectors. Scholarship has identified two dominant models of evidence-based practice. The first model refers to the evidence-based practice model (EBP), corresponding with the utilization of manualized and prescriptive clinical interventions with established fidelity procedures that have been shown to be efficacious through systematic reviews or controlled evaluation research (Barth et al., 2012). There is a large literature on understanding factors supporting implementation and practitioner use of EBPs (e.g., Aarons, Hurlburt, \& Horwitz, 2011; Palinkas et al., 2011).

The second model features evidence-informed practice as a multistep process through which practitioners integrate available client-based information and other agency data, external research, and their own practice experience with the goal of answering researchable practice questions (Gambrill, 2012). Scholarly attention to this model has informed an empirical literature on the questions of practitioner evidence use in social work and allied human service settings as well as strategies to support practitioner evidence use. Research in this area has explored the following: methods for locating external research and internal agency information (Thorsteinsson \& Sveinsdottir, 2012); practitioner attitudes about evidence use and EBP (Aarons, Cafri, Lugo, \& Sawitzky, 2012); use of technology to support research retrieval and use (Doran et al., 2012); use of research evidence for practice improvements (Parrish \& Rubin, 2012); and practitioner engagement in conducting agency-based research (Epstein, 2010). In addition, the identification of leadership and organizational cultural factors that promote practitioner involvement in evidence-informed activities has received increased attention (Austin et al., 2012).

Table 1 reviews recent quantitative studies on practitioner evidence use in health and human service settings; Squires and colleagues (2011) reviewed prior research on health care research utilization. A consideration of this research suggests four points. First, studies have conceptualized evidence use broadly, including generic use of research in practice (Chagnon, Pouliot, Malo, Gervais, \& Pigeon, 2010), involvement in agency performance measurement (Collins-Camargo, Sullivan, \& Murphy, 2011; Moynihan \& Lavertu, 2012) and use of agency outcome data (Lee, Bright, \& Berlin, 2013), and retrieval and use of research evidence to support informed decision making (Doran et al., 2012; Parrish \& Rubin, 2011, 2012). 


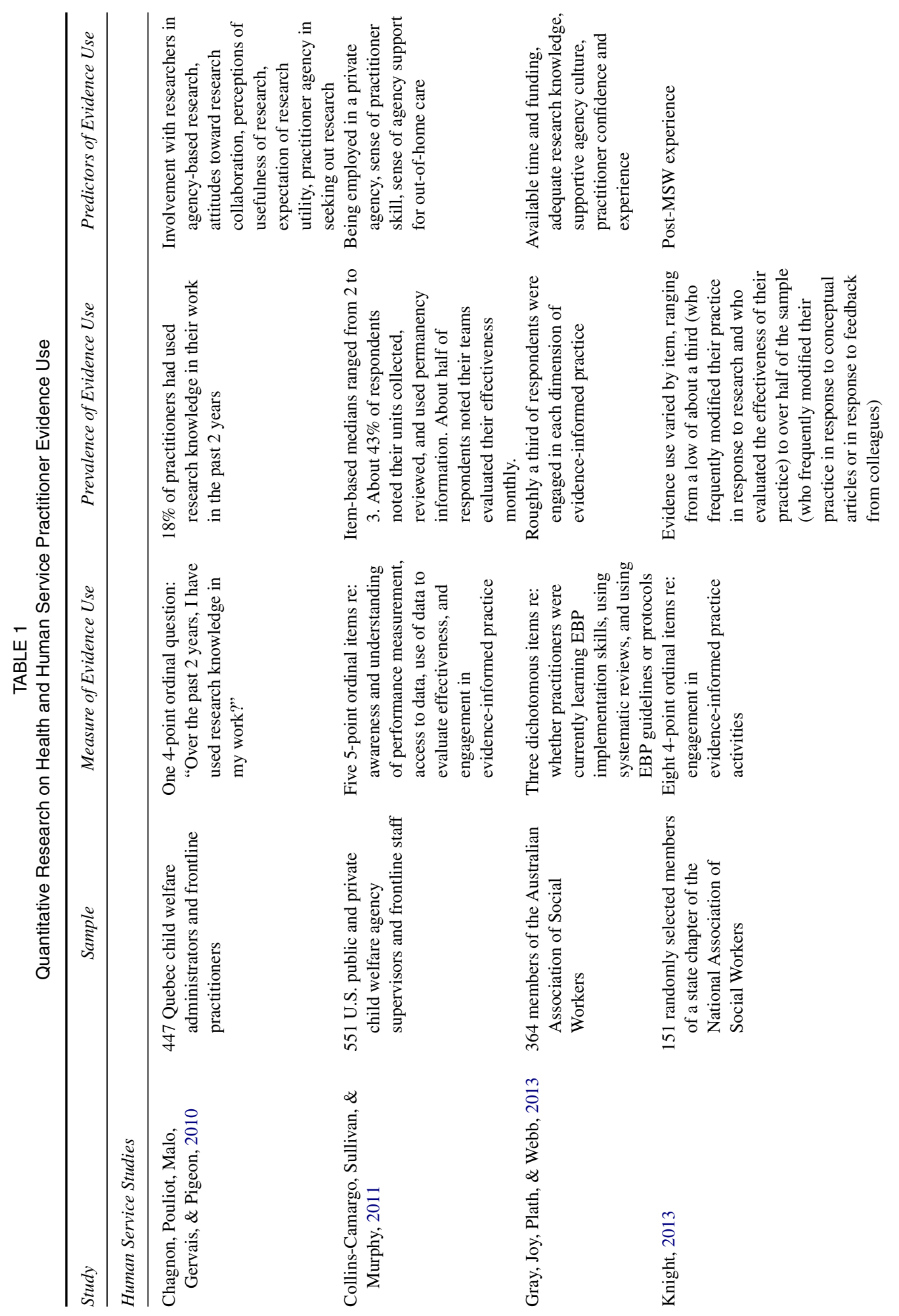




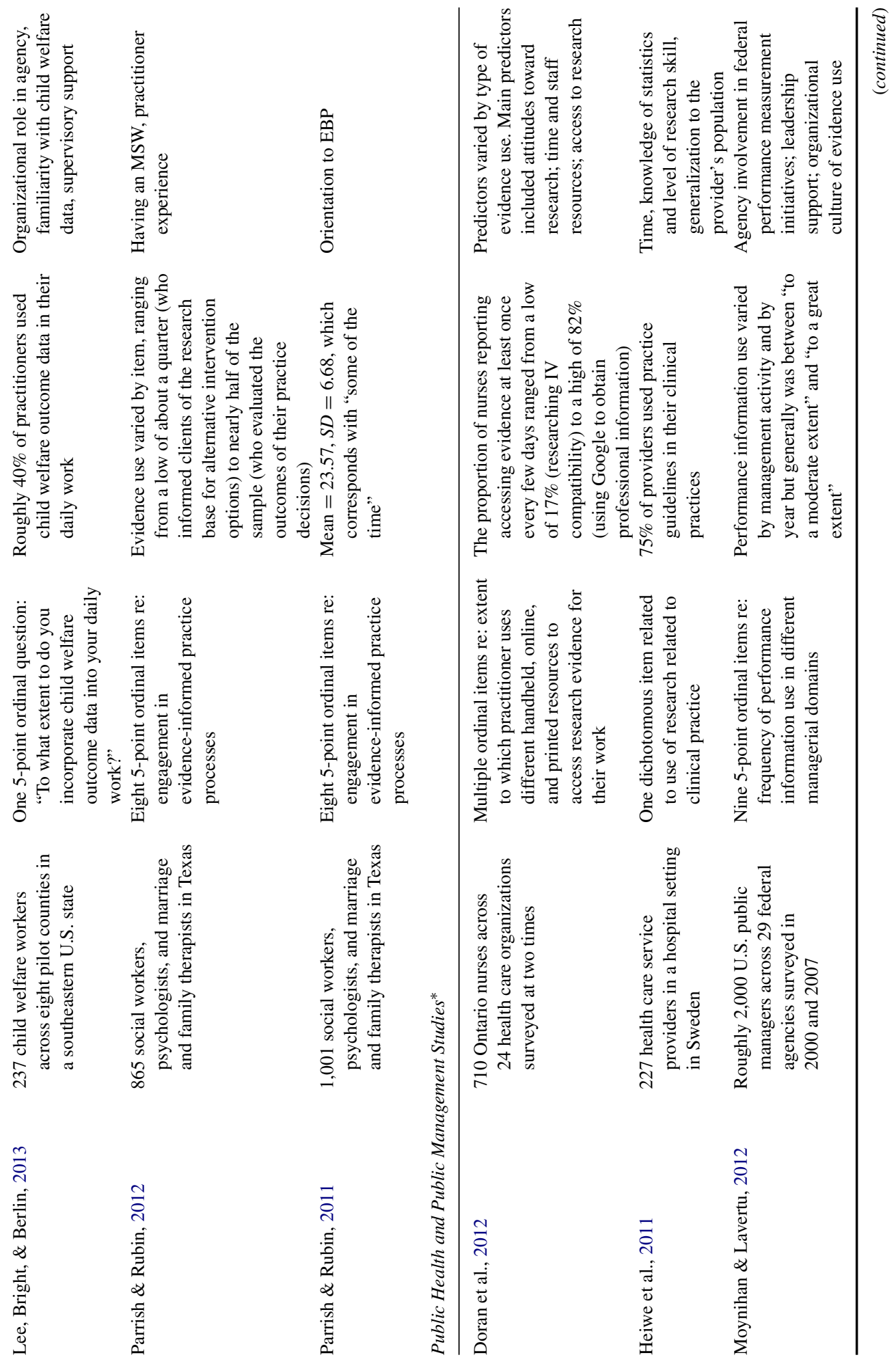




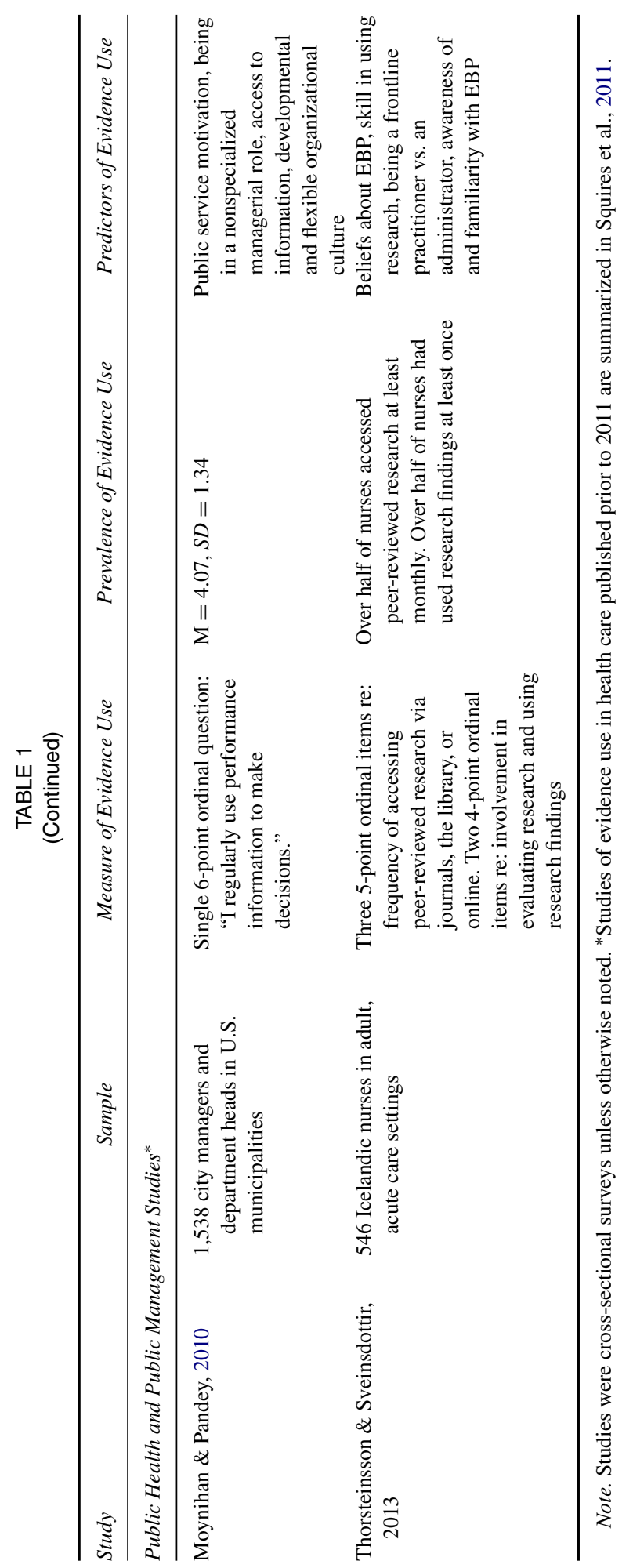


Second, studies have found variation in evidence use overall and by type of evidence, indicating that engagement in evidence-informed practice is not distributed equally across practitioners or organizations. Similarly, the use of multi-item measures of practitioner evidence use has suggested that evidence use differs by indicator, which may conceptualize and measure evidence use differently (Squires et al., 2011). In essence, multiple interrelated processes may exist within the overarching construct of evidence use.

Third, the goals of evidence use remain unclear. Studies have assumed that practitioners use evidence purposefully but have not always gathered data on why practitioners try to incorporate evidence into their practice. With respect to the purposes of evidence use, Nutley and colleagues conceptualized three primary purposes of evidence use: instrumental use, in which research is used to enhance individual practice and decision making; conceptual use that deepens the understanding of practitioners about their own practice; and advocacy use, in which research evidence is used to spur public advocacy and political communication (Nutley et al., 2007). Moynihan and Lavertu (2012) offered a similar conceptualization of purposeful use of performance information in federal agencies; managers may, for example, use evidence to set agency priorities and performance goals, problem solve, and/or initiate new work routines. Other scholars have differentiated between (a) practitioners applying research and other types of evidence to enhance agency services and their own practice efforts and (b) practice research in which traditional research and other knowledge development activities are used to identify solutions to organizational dilemmas (Epstein, 2010; McBeath \& Austin, in press).

Fourth, little research has focused on evidence use by human service managers. Research has also not specifically tested whether managers at different organizational levels and with different attitudes differ in their orientation to evidence, even though managers as a group are heterogeneous. Given that the managerial role is consistently noted as being important for facilitating frontline practitioner evidence, the lack of research identifying the characteristics of managers who are most involved in evidence use-and thus most likely to be champions of evidence-informed practice throughout human service organizations-is unfortunate.

Consideration of evidence use by human service managers also highlights the importance of situating evidence-informed practice within a goal-oriented organizational context in which managerial activities are designed to enhance knowledge that contributes to effective organizational change and innovation (Austin, 2008). Two organizational processes are involved. First, managers need to transition from knowing to doing by putting new knowledge into practice (Nutley et al., 2003). This process involves at a minimum consideration of the type of new knowledge being shared, organizational receptivity to that information, and the degree to which facilitation of learning is present (Rycroft-Malone et al., 2002). Second, knowledge-based managerial innovations need to be reinforced through informal norms and formal organizational mechanisms (Moynihan, 2008; Zahra \& George, 2002). This often requires institutional support from existing agency leaders, funding, and policy.

In human service organizations, evidence use is often directed at resolving critical management issues relating to the fundamental indeterminacy of service delivery. The complexity of service programming is often compounded by the following factors: (a) incomplete understanding of client needs; (b) lack of clarity regarding best practices to respond to needs and achieve desired outcomes; (c) uncertainty regarding how services are to be implemented to achieve effectiveness; (d) incomplete knowledge of past and current organizational practices and their success or failure; and (e) significant practitioner discretion (Hasenfeld, 2010; Sosin, 2010; Taylor \& White, 2006). The portrait that emerges is one of managers using different types of evidence to resolve practice dilemmas and to support frontline and programmatic improvements in service delivery (Shaw \& Faulkner, 2006). At an organizational level, the idea is that investment in managerial evidence use will spur agencywide learning and practice improvement (Nutley et al., 2007). 


\section{Factors Promoting Evidence Use}

The question is therefore how to identify those human service managers who are most involved in utilizing evidence to make progress toward these diverse goals. Organizational research on this question has sought to describe the contexts in which practitioners are more likely to have access to and use evidence. In contrast, research from the perspective of individual practitioners has sought to understand their attitudes toward and experiences with EBP and research evidence. These bodies of research can be differentiated by the degree to which they focus on the organizational determinants of access to evidence versus the individual-level drivers of evidence use (Chagnon et al., 2010).

\section{Organizational Factors Promoting Access to Evidence}

Many studies have identified the importance of organizational supports for promoting practitioner access to evidence. As noted in Table 1, research has found that locating, appraising, and integrating evidence into practice requires time and training, neither of which may be available to practitioners unless such undertakings receive support (Doran et al., 2012; Gray et al., 2013). Existing research has clearly identified the importance of external factors that incentivize or require evidence use, including funding, policy dicta, and institutional expectations (Aarons et al., 2011; Moynihan \& Lavertu, 2012).

This study focuses in contrast on internal organizational factors-particularly performance measurement systems and administrators - in an effort to provide an initial test of their association with levels of evidence use among human service managers. First, while performance measurement systems differ, their implementation may provide a technical foundation that promotes access to within-agency evidence. Through the development and utilization of multidimensional data dashboards, performance measurement systems generally involve the collection, analysis, and reporting of critical information concerning agency and program outputs (Hatry, 2007). Gathering and reporting these data often involves managerial staff throughout the agency, which may increase opportunities for and engagement with agency-based data and other forms of evidence (Carnochan et al., 2013).

However, Moynihan (2008) cautioned that agency involvement in performance measurement need not lead managers to use performance information or to an agencywide culture of evidence use. Empirical studies have presented mixed findings. Moynihan and Lavertu (2012) found that public managers involved in federal performance management initiatives are more involved in refining performance measurement processes but no more involved in using agency data for program and employee management. In contrast, LeRoux and Wright (2010) found that nonprofit directors rating their organizations highly in the use of performance measures are more likely to suggest that their agencies were making effective strategic decisions. In a systematic review of managerial performance information use, Kroll (2014) concluded that information use is enhanced in the presence of well-designed performance measurement systems (i.e., with clear goals, achievable targets, and face valid and easy to access indicators). These studies suggest the need for further research on the relationship between performance measurement and managerial evidence use.

Second, we expect differences in use of evidence by formal organizational role, with human service administrators in particular having potentially greater access to external research and withinagency evidence as compared to entry-level managers such as supervisors. Administrators can play a critical role in supporting the use of evidence. At a basic level, the administrative role is critical for authorizing the time and resources needed to invest in research, gathering and deploying resources to support evidence retrieval, and identifying agency research needs for programs and initiatives (Birkin, Lee, \& Weiner, 2012; McBeath \& Austin, in press).

Beyond these formal organizational functions, however, administrators may play key roles as champions of evidence-informed practice if they demonstrate leadership in linking evidence use 
to organizational performance. Moynihan and colleagues (Moynihan, Wright, \& Pandey, 2012) found that transformational leaders promote evidence use indirectly by facilitating goal clarity (around performance targets and pathways) and by supporting a performance-focused organizational culture. This basic finding is supported by other studies referenced in the systematic review conducted by Kroll (2014) as well as research on practitioner evidence use in the human service sector (Palinkas et al., 2011). Research has identified other mechanisms through which agency leaders involve themselves in evidence-informed practice due to the likelihood that they (a) serve as agency representatives for research-based initiatives involving external researchers; (b) are formally responsible for searching for promising practices and identifying evidence-based strategies for responding to current agency dilemmas; (c) oversee data collection and reporting with respect to performance measurement; and (d) organize within-agency communities of learning around professional development and research evidence due to their knowledge of the needs of organizational divisions and key staff (Aarons et al., 2011; Austin et al., 2012; Maynard, 2010).

Each of these possibilities suggests that administrators, in contrast to junior managers, may be not only involved in developing organizational supports for evidence use but also actively engaged in evidence retrieval, use, and dissemination. A few studies have found support for the contention that human service managers use evidence more than other agency staff (Lee et al., 2013; Moynihan \& Pandey, 2010; Thorsteinsson \& Sveinsdottir, 2013). However, because no study of human service practitioner evidence use has differentiated between administrators, middle managers, and supervisors and because few studies have controlled for individual covariates of formal organizational role (such as professional experience), additional research is warranted.

\section{Individual Factors Promoting Evidence Use}

As noted in Table 1, studies have found that evidence use is associated with a set of individual factors that predispose practitioners to be more comfortable with the research process and interested in acquiring and using research. These factors include practitioner perceptions of (a) the usefulness of research and collaboration with researchers (Chagnon et al., 2010); (b) skill as a practitioner (Collins-Camargo et al., 2011); (c) skill and confidence in using and evaluating research (Gray et al., 2013); (d) relevance and usefulness of practice research (Humphries, Stafinski, Mumtaz, \& Menon, 2014; Thorsteinsson \& Sveinsdottir, 2013); and (e) degree of public service motivation (Moynihan $\&$ Pandey, 2010). Because no study has been able to disentangle these correlates of evidence use, no consistent understanding has emerged from the literature concerning how these factors inform evidence use.

We seek to identify the benefit of two specific individual motivational factors for practitioner evidence use: innovation-mindedness and responsiveness to organizational change. Prior research has not examined the influence of these factors on human service managerial evidence use, despite suggestions that the intrinsic beliefs of managers impact managerial decision making (Moynihan \& Pandey, 2010). Following Rogers (2003), we define an innovation as an idea, practice, or object that is perceived as new within a specific social setting, and we understand innovation-mindedness to refer to the willingness of practitioners to search for and incorporate innovations into their repertoire of daily activity. The essential link between innovation and evidence use is the ability to identify a need for new information and the value of new approaches to practice. To use evidence purposively, practitioners may search for and apply evidence to identify alternatives to the status quo as well as novel approaches to current practice dilemmas. This process involves an assessment of whether the current knowledge base for practice is sufficient to the task; it may also focus the practitioner on the question of whether current organizational routines should be changed (Austin, 2008; RycroftMalone et al., 2002).

Innovation-minded managers may be more willing to engage in the process of using different types of evidence from inside and outside the organization to search for new practice approaches. 
In their review of the literature, Patterson, Kerrin, and Gatto-Rouissard (2009) suggested that innovation is a critical resource for organizational change and effectiveness and can be used to spur organizational growth. They also argued that innovation-minded practitioners are open to change and motivated to engage in problem solving. Doran and colleagues (2012) found that practitioners use more evidence if they believe that research is important for practice even if it conflicts with their training and organizational practices. This research implies that innovation-minded practitioners may actively search for evidence to support the process of experimentation (Austin et al., 2012).

The second factor we explore in relation to evidence use is the responsiveness of managers to organizational change. The ability to adapt to changing organizational circumstances is a central aspect of evidence-informed practice in complex human service contexts. Individuals who show a willingness to respond to changing practice settings may be more likely to demonstrate reflexivity, which Taylor and White (2006) defined as the ability to engage in critical self-analysis and which they and others have deemed essential for managerial excellence (Alvesson, Hardy, \& Harley, 2008; Schon, 1983). Practitioners who are responsive to change may also have the agency and autonomy to act strategically (Patterson et al., 2009; Sosin, 2010). These qualities of reflexivity, agency, and discretion may lead managers to locate and use evidence actively (Wilson, 2011).

\section{METHODS}

\section{Study Context}

This study used quantitative data from the Survey of Evidence-Informed Practice in the Human Services that was conducted June-July 2013 with public managers employed in 11 Bay Area county public human service organizations. The survey was sponsored by the Bay Area Social Services Consortium (BASSC), a research-based consortium of Bay Area universities and these 11 county human service organizations. The 11 county organizations are responsible for the administration and delivery of child welfare, employment and benefits, and adult and aging services. In addition, three of the agencies are responsible for county health service delivery. Agency size varies substantially across the county organizations, with budgets ranging from $\$ 93$ million to $\$ 738$ million and staff sizes ranging from 350 to 2,200 full-time employees.

This study took place in the post-Great Recession era as each county was coming out of a 5year period of sustained budget reductions and in the midst of conceiving a new business model for public human services. Much of the budget-cutting experience is captured in a recent study of the impact of the Great Recession (Graaf, Carnochan, Radu, \& Austin, 2014), which identified the following major findings: (1) lack of financial literacy among middle and senior managers; (2) limited communication mechanisms needed to manage the impact of the recession on public social services; and (3) insufficient use of technology for timely budgeting and communications. All three findings relate to the importance of evidence-informed management practice and managerial roles in public human service organizations.

An additional factor contextualizing our study was the long-standing vision among the 11 county agency directors to transform from public bureaucracies into learning organizations. Prior to the Great Recession, counties began to take stock of their current organizational development needs to build knowledge-sharing systems in support of evidence-informed practice (Austin, Claassen, Vu, \& Mizrahi, 2008; Claassen \& Austin, 2008; Lee \& Austin, 2012). Because the process of organizational change was delayed by the budget-cutting demands of the Great Recession from 2007 to 2012, this study of evidence-informed practice could only emerge in 2013. 


\section{Sample and Data Collection}

The purposive, nonprobability sample included staff from the 11 county public human service organizations who were employed in the child welfare, employment and benefits, and adult and aging service areas, as well as those in analyst or administrative support (e.g., fiscal) divisions. Each county director sent an email invitation to participate to employees at the executive, midmanagerial (e.g., program development and oversight), and supervisory (e.g., direct program implementation and supervision of frontline staff) levels. In addition, 3 of 11 county directors invited frontline (e.g., direct service provision) staff to participate; these frontline practitioners were not included in the current study sample given our focus on understanding managerial evidence use. A total of 497 of 958 invited employees completed the online survey. As a result, the survey had an estimated 52\% response rate, which is considered above average in surveys of agency managers (Baruch \& Holton, 2008).

Study participants completed the online Survey of Evidence-Informed Practice in the Human Services. This survey sought to understand how human service practitioners use agency information and other types of evidence (including research) to inform their practice and enhance services and agency operations. The survey contained closed- and open-ended questions in four domains of interest: practitioner demographic characteristics; practitioner opportunities for learning and creativity at work; use of research evidence at work; and professional development needs related to evidenceinformed practice. To promote its relevance to management practitioners, the survey instrument was first piloted with a sample of seven research and evaluation specialists, followed by review by over 30 mid-level managers, in the participating agencies. The instrument was then refined based on feedback from these two groups of managers before being shared with the current study participants.

The current study reports on the quantitative data derived from responses to the closed-ended questions. A separate paper describing the qualitative survey findings is in preparation.

The study was conducted in accordance with human subjects protection procedures through the institutional review board at the home institution of the third and fourth authors.

\section{Measures: Evidence Use}

The study dependent variable concerned the frequency with which respondents engaged in 11 evidence-informed practices organized conceptually into three domains reflecting different types and purposes of evidence use. These domains reflected the studies reviewed in Table 1 as well as the literature on evidence-informed practice. The first domain of gathering and reviewing agency data and external evidence reflected research focusing on practitioner efforts to gather different types of evidence and evaluate the utility of this information for resolving practice problems (Epstein, 2010; Gambrill, 2012; Thorsteinsson \& Sveinsdottir, 2012). Four items were included in this domain: (1) reviewing agency reports containing information such as quarterly statistics to see how the agency is performing in key areas; (2) conducting literature reviews to look for answers to researchable questions; (3) using and searching online databases to identify promising practices; and (4) reviewing case records from past and/or current clients to see how they are being served.

The second domain of developing and carrying out agency-based research reflected scholarship concerning the role of practitioners in conducting organizational research in support of program improvement and client service enhancement (Austin et al., 2012; Lee et al., 2013; Maynard, 2010; McBeath \& Austin, in press). Four items were included in this domain. They are: (5) surveying clients to assess their needs; (6) conducting program improvement studies to see if the agency is delivering services the best way possible; (7) conducting outcome studies to see whether agency services and programs are affecting client as intended; and (8) developing researchable questions in response to current agency needs. 
The third domain of involving key stakeholders in research was informed by studies documenting the important roles of external researchers, service users, and other organizational constituencies in developing and carrying out agency-based research (Austin, 2008; Chagnon et al., 2010; Lee \& Austin, 2012; Shaw \& Faulkner, 2006). Three items were included in this domain. They are: (9) involving clients in evaluating programs and services; (10) involving clients in planning and improving programs; and (11) involving outside researchers to help improve agency practices and impacts.

Each of these 11 items used an ordinal response scale where $1=$ none, $2=$ a little, $3=$ sometimes, $4=$ frequently, and $5=$ constantly. Because the overall measure had strong internal consistency ( $\alpha=0.87$ ), individual item scores were averaged to develop an omnibus measure of evidence use.

\section{Internal Organizational Factors Predicting Evidence Use}

Performance measurement environment. In seeking to determine if the respondent worked in a program engaged in performance measurement, a binary variable was coded $=1$ if the respondent perceived that his or her program used a performance dashboard or other regular report to display and keep track of important agency information about clients, services, and outcomes.

Work role. Respondents were asked to identify where they spent most of their time in terms of current work responsibilities. This variable capturing the primary work role of each respondent included categories for supervision (referent), middle management, and administrative role (i.e., executive team or administrative support).

\section{Individual Motivational Factors Predicting Evidence Use}

Innovation-mindedness. To determine whether a respondent approached his or her work in an innovative manner, a binary measure was coded $=1$ if the respondent strongly agreed with each of the following dichotomous questions: "I often search for new ideas to use in my work"; and "I make use of new ideas when people send me interesting information" (Patterson et al., 2009).

Responsiveness to organizational change. An additive scale was used to measure the perceived responsiveness of individuals to organizational change. Respondents were asked to identify which of the following strategies they would adopt in response to a major change in service demand (e.g., a large increase or decline in the county client population): (1) conduct a survey of coworkers; (2) conduct a survey of clients; (3) conduct a survey of community providers; (4) contact researchers with expertise in the area; (5) review client case records; (6) review agency reports; (7) review research articles and reports; and/or (8) employ another strategy to search for explanations. The number of strategies noted by respondents was summed into a count variable, with higher values indicating increased responsiveness to organizational change.

\section{Other Covariates}

In order to account for differences in evidence use based on years of experience, a continuous variable was included reflecting the number of years that the respondent had worked in the human service sector at the time of the survey (Knight, 2013).

A categorical variable of education captured whether the respondent had less than a bachelor's degree, a bachelor's degree (i.e., BSW, BA, or BS degree), an MSW degree (referent), or some other master's degree. This variable was included based on prior research suggesting that MSW training can be associated with evidence use and evidence-informed practice (Parrish \& Rubin, 
2012). An additional binary variable measured whether the respondent held a $\mathrm{PhD}$ or another doctoral degree (e.g., DSW) but this variable was not included in multivariate models due to small cell counts. (As part of sensitivity analyses, models with and without the $\mathrm{PhD}$ variable were run and provided similar results).

A set of demographic variables was included to capture differences in individual respondent characteristics. Gender was operationalized as a binary variable indicating whether the respondent self-identified as female. Race/ethnicity was measured through a binary variable indicating whether a respondent self-identified as a person of color (i.e., African American, Hispanic, American Indian, Asian, Native Hawaiian/Pacific Islander, or some other race/ethnicity). To account for covariation between age, years of work experience, and formal work role, a categorical variable indicated whether the respondent's age was less than 40 years, between 40 and 54 years, or over 55 years (referent).

\section{Analyses}

Descriptive and bivariate statistics were first used to describe the full sample and differentiate between managers engaged in different levels of evidence use. A multivariate regression model was then used to examine the hypothesized associations between the identified independent variables and the frequency of evidence use. The model included Huber-White robust standard errors to account for potential multicollinearity resulting from the clustering of responses at the organizational level across the 11 county (public) human service organizations.

Insufficient numbers of observations within the highest categories of the outcome variable necessitated its transformation from a 5-point scale to a binary measure (set $=1$ if respondents reported an average of "sometimes", "frequently" or "constantly" responses on frequency of evidence use, and with all else set $=0$ ). (Originally, multivariate ordinal logistic regressions were run with the nontransformed dependent variable and the full predictive model. Post hoc tests indicated that the model did not pass the Brant test, suggesting a violation of the proportional odds assumption). Multivariate logistic regressions were thus employed, followed by two sensitivity tests. The linktest specification test did not detect specification errors in the logistic model. Additionally, Hosmer and Lemeshow's Goodness of Fit test was run to test for model fit, which was determined to be satisfactory (Cameron \& Trivedi, 2009).

Phi and biserial correlations between independent variables were all less than $r=0.47$. Although survey item nonresponse was generally quite low and did not exceed $4 \%$ for any given predictor or covariate, availability of data in the dependent variable reduced the final sample for statistical analysis to 385 managers. Multiple imputation using the multivariate normal imputation method was implemented to reduce potential bias from missing data and maintain the full analytic sample (Allison, 2002; Lee \& Carlin, 2010). Twenty imputations were used to reduce sampling error and the outcome variable was included in the imputation procedure to maximize the information used during the imputation process (Von Hippel, 2007). The presented multivariate results reflect the imputed data set. All analyses were conducted using Stata 13.0 (StataCorp, 2011).

\section{RESULTS}

\section{Descriptive and Bivariate Results}

Table 2 presents summary statistics for the full sample. Using the binary dependent variable (where $1=$ an average of at least some use of the 11 evidence-informed practices), over one third of respondents $(37 \%, n=142)$ reported some or more evidence use. Looking at responses to the individual items comprising the overall measure of evidence use, most managers noted that they used evidence 
TABLE 2

Descriptive Characteristics of Human Service Managers

\begin{tabular}{|c|c|c|c|c|}
\hline & $N$ & $\%$ & Mean $(S D)$ & Rang \\
\hline \multicolumn{5}{|l|}{ Outcome Variable } \\
\hline Some to frequent use of evidence-informed practices & 385 & $37 \%$ & & $0-1$ \\
\hline \multicolumn{5}{|l|}{ Evidence-Informed Practice Items } \\
\hline \multicolumn{5}{|c|}{ Gathering and Reviewing Agency Data and External Evidence } \\
\hline $\begin{array}{l}\text { Reviewing agency reports containing information such } \\
\text { as quarterly statistics to see how the agency is doing } \\
\text { in key areas }\end{array}$ & 378 & & $3.20(1.24)$ & $1-5$ \\
\hline $\begin{array}{l}\text { Reviewing case records from past and/or current } \\
\text { clients to see how they are being served }\end{array}$ & 381 & & $2.29(1.18)$ & \\
\hline $\begin{array}{l}\text { Conducting literature reviews to look for answers to } \\
\text { my questions }\end{array}$ & 382 & & $2.73(1.22)$ & \\
\hline $\begin{array}{l}\text { Using and searching online databases to identify } \\
\text { promising practices }\end{array}$ & 385 & & $2.68(1.11)$ & \\
\hline
\end{tabular}

Developing and Carrying Out Agency-Based Research

\begin{tabular}{llll}
\hline $\begin{array}{l}\text { Surveying clients to assess their needs } \\
\text { Conducting program improvement studies to see if the } \\
\quad \text { agency is delivering services the best way possible }\end{array}$ & 382 & $2.28(1.15)$ & $1-5$ \\
$\begin{array}{l}\text { Conducting outcome studies to see whether agency } \\
\quad \text { services and programs are affecting clients as }\end{array}$ & 379 & $2.24(1.22)$ & $1-5$ \\
$\quad \begin{array}{l}\text { intended } \\
\text { Developing researchable questions in response to }\end{array}$ & 376 & $2.16(1.24)$ & $1-5$ \\
$\quad$ agency needs & & $2.03(1.20)$ & $1-5$ \\
\hline $\begin{array}{l}\text { Involving Key Stakeholders in Research } \\
\text { Involving clients in evaluating programs and services }\end{array}$ & 376 & & \\
Involving clients in planning and improving programs & 373 & $2.07(1.10)$ & $1.02(1.14)$ \\
Involving outside researchers to help improve agency & 374 & $1.97(1.12)$ & $1-5$ \\
$\quad$ practices and impacts & & & $1-5$ \\
\hline
\end{tabular}

Within-Organization Factors

\begin{tabular}{llll}
\hline Performance measurement environment & 377 & $76 \%$ & $0-1$ \\
Work role & & & \\
$\quad$ Supervision (Referent) & 385 & $42 \%$ & $0-1$ \\
$\quad$ Middle management & 385 & $30 \%$ & $0-1$ \\
$\quad$ Administration & 385 & $28 \%$ & $0-1$ \\
\hline Individual Factors & & $39 \%$ & $0-1$ \\
\hline Innovation-mindedness & 385 & $4.02(1.97)$ & $0-8$ \\
Responsiveness to organizational change & 385 & & $18.24(9.43)$ \\
\hline Covariates & & & $0-44$ \\
\hline Number of years employed in the human service & & \\
$\quad$ sector & 384 & & \\
\hline
\end{tabular}


TABLE 2

(Continued)

\begin{tabular}{|c|c|c|c|c|}
\hline & $N$ & $\%$ & Mean $(S D)$ & Range \\
\hline \multicolumn{5}{|l|}{ Education } \\
\hline Less than a bachelor's degree & 385 & $14 \%$ & & $0-1$ \\
\hline Bachelor's degree & 385 & $24 \%$ & & $0-1$ \\
\hline MSW degree (Referent) & 385 & $34 \%$ & & $0-1$ \\
\hline Other master's degree & 385 & $25 \%$ & & $0-1$ \\
\hline Female & 370 & $73 \%$ & & $0-1$ \\
\hline \multicolumn{5}{|l|}{ Race/ethnicity } \\
\hline Caucasian (Referent) & 385 & $53 \%$ & & $0-1$ \\
\hline Person of color & 385 & $47 \%$ & & $0-1$ \\
\hline \multicolumn{5}{|l|}{ Age } \\
\hline Less than 40 years old & 383 & $17 \%$ & & $0-1$ \\
\hline Between 40 and 54 years old & 383 & $54 \%$ & & $0-1$ \\
\hline Age 55 years old and older (Referent) & 383 & $29 \%$ & & $0-1$ \\
\hline
\end{tabular}

from "a little" to "sometimes." The highest frequency of the use of evidence related to reviewing agency reports (mean $=3.20, S D=1.24$ ). In comparison, the lowest frequency of evidence use involved the use of outside researchers (mean $=1.97, S D=1.12$ ). Among the three domains of evidence use, managers were more engaged in gathering and reviewing agency data and external evidence than carrying out agency-based research or involving key stakeholders in research.

With respect to performance measurement, most managers $(76 \%, n=293)$ were working in a program that used a data dashboard or some other regular reporting system to display and keep track of important agency information about clients, services, and outcomes. The majority of respondents were in a supervisory work role $(42 \%, n=161)$. Nearly two-fifths of managers were classified as innovation-minded $(39 \%, n=150)$; and respondents noted on average four activities (mean $=4.02$, $S D=1.97$ ) that they would carry out in response to a major organizational change. Respondents had on average 18 years of work experience (mean $=18.24, S D=9.43)$ and the most common educational degree held by respondents was a MSW master's degree $(34 \%, n=130)$. Most managers were female $(73 \%, n=281)$, Caucasian $(53 \%, n=204)$, and between the ages of 40 and 54 at the time of the survey $(54 \%, n=208)$.

The bivariate comparisons presented in Table 3 provide a descriptive profile of managers using more versus less evidence. As expected, those who engaged in moderate to considerable use of evidence were more involved in each of the 11 evidence-informed practices when compared with practitioners who used little or no evidence. Evidence-using managers were also more likely than others to be in a performance measurement environment (84\% vs. 70\%), in an administrative role ( $40 \%$ vs. $21 \%)$, innovation-minded (55\% vs. $30 \%)$, and responsive to organizational change (4.75 vs. 3.59$)$. They also had longer tenures in the human services (19.81 vs. 17.31 years) and were, on average, older (35\% vs. $26 \%$ ).

\section{Multivariate Results}

Table 4 presents results of multivariate logistic regression analyses. As seen in the table and holding other factors constant, managers involved with programs with performance measurement systems reported greater odds of evidence use $(\mathrm{OR}=2.33, p<0.01)$. In addition, formal organizational roles were significantly associated with evidence use, with administrators reporting being more engaged in evidence use as compared to supervisors $(\mathrm{OR}=1.92, p<05)$. 
TABLE 3

Sample Characteristics by Level of Managerial Evidence Use

\begin{tabular}{|c|c|c|c|}
\hline & $\begin{array}{l}\text { No to Little } \\
\text { Evidence Use } \\
(\mathrm{n}=243,63 \%)\end{array}$ & $\begin{array}{l}\text { Some to Frequent } \\
\text { Evidence Use } \\
(\mathrm{n}=142,37 \%)\end{array}$ & \\
\hline & $\begin{array}{c}\text { Mean (SD) } \\
\%\end{array}$ & $\begin{array}{c}\text { Mean }(\mathrm{SD}) \\
\%\end{array}$ & $\mathrm{P}$-value \\
\hline \multicolumn{4}{|l|}{ Evidence-Informed Practice Items } \\
\hline \multicolumn{4}{|l|}{ Gathering and Reviewing Agency Data and External Evidence } \\
\hline $\begin{array}{l}\text { Reviewing agency reports containing information such } \\
\text { as quarterly statistics to see how the agency is doing } \\
\text { in key areas }\end{array}$ & $2.74(0.08)$ & $4.00(0.08)$ & $0.000^{* * *}$ \\
\hline $\begin{array}{l}\text { Reviewing case records from past and/or current } \\
\text { clients to see how they are being served }\end{array}$ & $1.87(0.07)$ & $2.98(0.09)$ & $0.000^{* * *}$ \\
\hline $\begin{array}{l}\text { Conducting literature reviews to look for answers to } \\
\text { my questions }\end{array}$ & $2.40(0.07)$ & $3.28(0.09)$ & $0.000^{* * *}$ \\
\hline $\begin{array}{l}\text { Using and searching online databases to identify } \\
\text { promising practices }\end{array}$ & $2.27(0.06)$ & $3.36(0.08)$ & $0.000^{* * *}$ \\
\hline \multicolumn{4}{|l|}{ Developing and Carrying Out Agency-Based Research } \\
\hline Surveying clients to assess their needs & $1.83(0.06)$ & $3.04(0.08)$ & $0.000^{* * *}$ \\
\hline $\begin{array}{l}\text { Conducting program improvement studies to see if the } \\
\text { agency is delivering services the best way possible }\end{array}$ & $1.64(0.05)$ & $3.27(0.09)$ & $0.000^{* * *}$ \\
\hline $\begin{array}{l}\text { Conducting outcome studies to see whether agency } \\
\text { services and programs are affecting clients as } \\
\text { intended }\end{array}$ & $1.05(0.05)$ & $3.28(0.09)$ & $0.000^{* * *}$ \\
\hline $\begin{array}{l}\text { Developing researchable questions in response to } \\
\text { agency needs }\end{array}$ & $1.43(0.05)$ & $3.05(0.10)$ & $0.000^{* * *}$ \\
\hline \multicolumn{4}{|l|}{ Involving Key Stakeholders in Research } \\
\hline Involving clients in evaluating programs and services & $1.55(0.05)$ & $3.00(0.08)$ & $0.000^{* * *}$ \\
\hline Involving clients in planning and improving programs & $1.49(0.05)$ & $2.93(0.09)$ & $0.000^{* * *}$ \\
\hline $\begin{array}{l}\text { Involving outside researchers to help improve agency } \\
\text { practices and impacts }\end{array}$ & $1.48(0.05)$ & $2.84(0.09)$ & $0.000^{* * *}$ \\
\hline \multicolumn{4}{|l|}{ Within-Organization Factors } \\
\hline $\begin{array}{l}\text { Performance measurement environment } \\
\text { Work role }\end{array}$ & $70 \%$ & $84 \%$ & $0.003^{* * *}$ \\
\hline Supervision & $47 \%$ & $34 \%$ & $0.009^{* *}$ \\
\hline Middle management & $32 \%$ & $27 \%$ & 0.27 \\
\hline Administration & $21 \%$ & $40 \%$ & $0.000^{* * *}$ \\
\hline \multicolumn{4}{|l|}{ Individual Factors } \\
\hline Innovation-mindedness & $30 \%$ & $55 \%$ & $0.000^{* * *}$ \\
\hline Responsiveness to organizational change & $3.59(0.13)$ & $4.75(0.14)$ & $0.000^{* * *}$ \\
\hline \multicolumn{4}{|l|}{ Covariates } \\
\hline $\begin{array}{l}\text { Number of years employed in the human service } \\
\text { sector }\end{array}$ & $17.31(0.57)$ & $19.81(0.85)$ & $0.011^{*}$ \\
\hline
\end{tabular}


TABLE 3

(Continued)

\begin{tabular}{|c|c|c|c|}
\hline & $\begin{array}{c}\text { No to Little } \\
\text { Evidence Use } \\
(\mathrm{n}=243,63 \%)\end{array}$ & $\begin{array}{c}\text { Some to Frequent } \\
\text { Evidence Use } \\
(\mathrm{n}=142,37 \%)\end{array}$ & \\
\hline & $\begin{array}{c}\text { Mean (SD) } \\
\%\end{array}$ & $\begin{array}{c}\text { Mean (SD) } \\
\%\end{array}$ & $\mathrm{P}$-value \\
\hline \multicolumn{4}{|l|}{ Education } \\
\hline Less than a bachelor's degree & $14 \%$ & $14 \%$ & 0.897 \\
\hline Bachelor's degree & $25 \%$ & $21 \%$ & 0.345 \\
\hline MSW degree & $34 \%$ & $33 \%$ & 0.838 \\
\hline Other master's degree & $24 \%$ & $28 \%$ & 0.383 \\
\hline Female & $74 \%$ & $72 \%$ & 0.763 \\
\hline \multicolumn{4}{|l|}{ Race/ethnicity } \\
\hline Caucasian & $50 \%$ & $57 \%$ & 0.237 \\
\hline \multicolumn{4}{|l|}{ Age } \\
\hline Less than 40 years old & $19 \%$ & $13 \%$ & 0.180 \\
\hline Between 40 and 54 years old & $56 \%$ & $51 \%$ & 0.426 \\
\hline Age 55 years old and older & $26 \%$ & $35 \%$ & $0.05^{*}$ \\
\hline
\end{tabular}

Note. ${ }^{*} p<0.05,{ }^{* * *} p<0.001$

TABLE 4

Multivariate Logistic Regression Predicting Overall Level of Evidence Use

\begin{tabular}{|c|c|c|c|c|c|}
\hline & OR & SE & $\mathrm{P}>|t|$ & \multicolumn{2}{|c|}{$95 \% C I$} \\
\hline \multicolumn{6}{|l|}{ Within-Organization Factors } \\
\hline Performance measurement environment & 2.33 & 0.66 & $* *$ & 1.34 & 4.06 \\
\hline \multicolumn{6}{|l|}{ Work role } \\
\hline Middle management & 1.01 & 0.15 & & 0.76 & 1.35 \\
\hline Administration & 1.92 & 0.53 & * & 1.11 & 3.32 \\
\hline \multicolumn{6}{|l|}{ Individual Factors } \\
\hline Innovation-mindedness & 2.36 & 0.37 & $* * *$ & 1.73 & 3.21 \\
\hline Responsiveness to organizational change & 1.27 & 0.07 & $* * *$ & 1.14 & 1.42 \\
\hline \multicolumn{6}{|l|}{ Covariates } \\
\hline $\begin{array}{l}\text { Number of years employed in the human service } \\
\text { sector }\end{array}$ & 1.02 & 0.01 & $*$ & 1.00 & 1.04 \\
\hline \multicolumn{6}{|l|}{ Education } \\
\hline Less than a bachelor's degree & 1.25 & 0.48 & & 0.59 & 2.65 \\
\hline Bachelor's degree & 1.09 & 0.36 & & 0.57 & 2.09 \\
\hline Other master's degree & 1.01 & 0.29 & & 0.58 & 1.78 \\
\hline Female & 1.03 & 0.38 & & 0.50 & 2.12 \\
\hline Caucasian & 1.08 & 0.24 & & 0.70 & 1.68 \\
\hline \multicolumn{6}{|l|}{ Age } \\
\hline Less than 40 years old & 0.69 & 0.32 & & 0.28 & 1.70 \\
\hline Between 40 and 54 years old & 0.69 & 0.19 & & 0.40 & 1.17 \\
\hline
\end{tabular}

Note. $N=385$. Average relative variance increase $(\mathrm{RVI})=0.26 .{ }^{*} p<0.05,{ }^{* *} p<0.01,{ }^{* * *} p<0.001$

The individual-level factors of innovation-mindedness and responsiveness to organizational change were associated with increased odds of evidence use $(\mathrm{OR}=2.36, p<0.001$ and $\mathrm{OR}=1.27$, $p<0.01$, respectively). One could argue that responsiveness to organizational change expressed by 
managers may differ by formal role, with administrators in particular having greater autonomy in suggesting needed organizational reforms. We implemented sensitivity checks to test the interaction of work role and responsiveness to organizational change using a post hoc Wald-type test (i.e., testnl) for nonlinear hypotheses after model estimation (StataCorp, 2011). No significant differences were found $(p=0.949)$.

Finally, the number of years of employment in the human service sector was associated with higher odds of evidence use ( $\mathrm{OR}=1.02, p<0.05)$. However, no significant differences in evidence use were found in relation to other professional and personal characteristics of managers.

\section{DISCUSSION}

This study was designed to increase our understanding of evidence use by managers in public human service settings. Our outcome variable was a multi-item measure reflecting attention to three domains of engagement in evidence-informed practice: gathering and reviewing agency data and external evidence; developing and carrying out agency-based research; and involving key stakeholders in research. In examining survey data from administrators, middle managers, and supervisors in 11 Bay Area county (public) human service organizations, we found that managers engaged in evidence use from "a little" to "sometimes," with managers most involved in reviewing agency reports, searching for research literature and other evidence, and using online resources to identify promising practices. In contrast, managers were less active in involving clients in program improvement efforts, developing researchable questions in response to agency needs, and collaborating with external researchers. Multivariate analyses with an overall measure of evidence use determined that evidence use was positively associated with having access to performance measurement systems and being an administrator versus a supervisor. Evidence use was also positively associated with managerial self-perceptions of innovation-mindedness, responsiveness to organizational change, and their level of seniority in the human service field.

\section{Limitations}

These findings should be understood in relation to a number of study limitations. First, as with most studies on practitioner evidence use, we used a measurement approach involving predominantly practitioner self-report to survey questions that were ordinal in nature. More objective measurements, as well as more fine-grained data collection methods (e.g., time diaries), may have allowed for more systematic assessment of evidence use. Measurement error may have also been present in the measures of innovation-mindedness and responsiveness to organizational change, which ideally would have been captured through objective indices as opposed to dichotomies. Second, due to the cross-sectional nature of the study design, we were not able to estimate the causal influence of the hypothesized organizational and individual-level predictors on evidence use. In addition, we were not able to develop and test a more elaborate model involving potential mediators and/or moderators of evidence use given the lack of clear temporal ordering of these survey data. Third, sample selection bias may have been present. Although overall survey response rates were robust, managers who were low evidence users may have been less likely to respond. This possibility implies that study findings may have been systematically biased toward more positive reports on critical variables than what was present in the population. Finally, while study findings were drawn from a large sample of managers at all levels of the 11 Bay Area county human service organizations, the generalizability of these findings to frontline practitioners in the Bay Area county organizations or to managers in other jurisdictions may be limited. 


\section{Synthesis and Implications}

This study provides a contribution to the literatures on human service managerial evidence use and evidence-informed practice. Our study reflected on the literature on evidence-informed practice, which has focused principally on the determinants of frontline practitioner evidence use to the neglect of questions concerning managerial involvement in promoting and engaging in evidenceinformed practice, and the literature on performance management and innovation in human service settings, which views performance information and evidence use as a strategy to promote managerial effectiveness in pursuing organizational goals.

Descriptively, findings underscore the purposive nature of evidence use by managers in public human service organizations. Practitioners described using internal and external sources of evidence to gain new knowledge for serving clients and to identify strategies to enhance agency performance. Other scholarship has described the importance of managers using diverse types of evidence to navigate complex human service settings in a reflective manner (Alvesson et al., 2008). Our study provides the first assessment of the extent to which human service managers use evidence for these different purposes. In the main, our findings suggest that managers are viewing evidence as useful for a variety of activities supporting frontline service enhancement and organizational improvement.

Levels of evidence use were modest, comporting with prior research. Only about a third of administrators, middle managers, and supervisors engaged in some-to-frequent evidence use, which might be considered low given that these were individuals who could reasonably be expected to have access to diverse types of evidence and face external and internal pressures to use evidence regularly. While managers were more engaged in gathering and reviewing agency data and external evidence than in developing and carrying out agency-based research or involving key stakeholders in research, overall item-level differences across the three domains of evidence-informed practice were generally less than a point (using 5-point Likerts). Standard deviations for each item were also in this range, suggesting the existence of a basic distribution of evidence use in the study sample.

Managerial engagement was greatest with sources of evidence commonly available in human service organizations, including agency reports, online databases, clients, and case records. These findings imply that managerial evidence use may be driven by the types of evidence most available within human service settings (Epstein, 2010). Scholars have argued that aligning practice within the hierarchy of evidence, in which research evidence from systematic reviews and randomized controlled trials, is to be preferred over other forms of evidence and agency-based sources that promote effective services (Heinrich, 2007). Others have identified the collection and evaluation of the best available research as a core aspect of evidence-informed practice (Gambrill, 2012). While it is possible that managers in our sample were accessing rigorous external research through online searches, their use of such research evidence would likely have been balanced by a strong reliance on available agency-based data.

Thus, managerial evidence use appears to be primarily informal, eclectic, and agency based. The lowest rated evidence-informed practices were engaging external researchers and conducting program and agency improvement studies. While it is not clear how deeply involved managers were in collaborating with other agency colleagues, most did not seem to be engaged in organized, research-intensive projects. Other research has suggested that practitioners may struggle to collaborate with external researchers due to practitioners viewing academic research as distant from frontline concerns (Shaw \& Faulkner, 2006; Taylor \& White, 2006).

Although the current study was not able to examine the question of how managers balanced their evidence search and use with their work responsibilities, the understanding of evidence use that emerges from the bivariate and multivariate analyses is of an activity that is contingent on organizational resources and organizational role. Most respondents reported having access to agency reporting systems such as performance dashboards; and those who acknowledged their presence 
were more likely to use evidence. Agency investment in such systems and in ensuring that performance measurement is both used and useful for practice and may help managers access and use agency-based and external evidence.

Administrators emerged in our analyses as critical for promoting evidence use within organizations. Given their role characteristics, senior managers are well positioned to champion evidence-informed practice by bridging external and internal sources of evidence that are needed to build knowledge-sharing systems, promote innovation in daily practice, and facilitate practitioner access to performance measurement systems. While it might seem self-evident that administrators might be more involved in tasks requiring evidence use than frontline supervisors, research has found that administrators may be barriers to evidence use and EBP implementation (Aarons et al., 2011; Birken et al., 2012). This difference in understanding of the administrative role suggests that the research has not conclusively determined that agency leaders are positive factors in evidence-based organizational reforms.

Our finding that public human service administrators were more likely than lower-level managers to use evidence also suggests that the administrative role in human service organizations may include evidence retrieval, use, and dissemination. This possibility implies that agency leaders may be called on to model evidence-informed practice regardless of whether their agencies are engaged in performance management. This line of inquiry suggests greater attention to the socialization and training of new and midlevel managers in evidence-informed practice to prepare them for the evidentiary demands of senior administrative posts. Clearly, the administrative role matters for practitioner evidence use and requires further investigation.

Finally, the individual-level factors associated with evidence use-innovation-mindedness and responsiveness to organizational change-highlight the motivational and attitudinal foundations of evidence-informed management practice. These findings also support prior research that suggests that evidence-informed practitioners are able to manage practice-based ambiguity and uncertainty to search for novel alternatives to current frontline and agency practices (Shaw \& Faulkner, 2006; Taylor \& White, 2006). Our findings suggest the importance of a sense of personal and professional agency as a potential spur for evidence use. Overall, we found that human service evidence use is more prominent in the presence of a motivated and responsive workforce with access to performance measurement systems and supported through an active administrative role.

\section{Future Directions for Research on Evidence-Informed Management Practice}

Research is needed to further describe the contexts and consequences of the use of available, agencybased data by human service managers. Under what conditions do managers use different types of evidence effectively to achieve their goals? How can they balance consideration of evidence quality and relevance within their organizational settings? Where are managers obtaining external evidence and to what extent are they combining internal and external evidence to develop innovative practice approaches? These questions direct scholars to develop richer accounts of managerial evidence use that (a) follow different types of managers over time to track changes in the nature and intensity of their evidence use, (b) evaluate the impacts of evidence use in relation to frontline and organizational outcomes, (c) avoid assuming that all evidence is equivalent or that one type of evidence is ideal across all practice settings and for all purposes, and (d) examine how evidence-informed practice can help managers navigate complex practice environments. Case-based and qualitative research will be helpful for answering these questions.

Future research is also needed to clarify the organizational determinants of evidence use. Multilevel conceptual models, in which attitudinal factors predisposing practitioner evidence use are hypothesized to be influenced by structural factors (e.g., organizational investment in evidence use, social norms, and networks supporting the development of learning communities) remain rare in the literature (for an exception, see Aarons et al., 2011). Empirical studies testing such models 
would be welcome in light of the lack of consideration of the organizational context of practitioner evidence use and evidence-informed practice. A contextual understanding of these practitioner processes might seek to understand how managerial efforts to engage in evidence-informed practice amidst ongoing work responsibilities are supported by (a) broad agency-based performance initiatives incentivizing evidence use as well as (b) more targeted efforts to locate and support critical evidence-informed practitioners.

Such models might focus scholarly attention on how critical organizational catalysts for evidence-informed practice (e.g., administrative champions, short-term sabbaticals to pursue agency-based research projects, dedicated training) are distributed across human service organizations and how these resources shape the context of managerial evidence use. It is likely that these supports predominate in performance-focused environments and competitive environments (Moynihan \& Lavertu, 2012). But it should not be presumed that organizations in common institutional environments respond similarly; nor should it be assumed that organizational leaders employ evidence supports identically or that these supports have similar effects on managers across diverse organizational settings.

These considerations suggest that future research might seek to illuminate the administrative role in practitioner evidence use and evidence-informed practice. Such efforts might focus on how agency leaders mediate or moderate the influence of organizational commitment and agency resources on individual attitudes about evidence use. This research might investigate the organizational factors enhancing managerial sense of empowerment when engaged in evidence-informed practice. Such future efforts might help clarify how human service organizational leaders support the transition from knowing to doing.

\section{CONCLUSION}

Promoting managerial evidence use is a strategy for enhancing effectiveness in human service organizations that is growing in importance in relation to policy-fiscal demands and performance management. Our findings confirm expectations derived from the literature on the organizational and individual attitudinal correlates of evidence use. These results suggest greater attention is needed to building knowledge-promoting and knowledge-sharing supports in human service organizations and to nurturing evidence-informed managers. Study findings also highlight the need for future research on the multilevel determinants of managerial use of different types of evidence.

\section{REFERENCES}

Aarons, G. A., Cafri, G., Lugo, L., \& Sawitzky, A. (2012). Expanding the domains of attitudes towards evidence-based practice: The Evidence Based Practice Attitude Scale-50. Administration and Policy in Mental Health, 39, 331-40.

Aarons, G. A., Hurlburt, M., \& Horwitz, S. M. (2011). Advancing a conceptual model of evidence-based practice implementation in public service sectors. Administration and Policy in Mental Health, 38, 4-23.

Allison, P. D. (2002). Missing data. Thousand Oaks, CA: Sage.

Alvesson, M., Hardy, C., \& Harley, B. (2008). Reflecting on reflexivity: Reflexive textual practices in organization and management theory. Journal of Management Studies, 45, 480-501.

Austin, M. J. (2008). Strategies for transforming human service organizations into learning organizations: Evidence-based practice and the transfer of learning. Journal of Evidence-Based Social Work, 5, 469-596.

Austin, M. J., Claassen, J., Vu, C., \& Mizrahi, P. (2008). Knowledge management: Implications for human service organizations. Journal of Evidence-Based Social Work, 5, 361-388.

Austin, M. J., Dal Santo, T. S., \& Lee, C. (2012). Building organizational supports for research-minded practitioners. Journal of Evidence-Based Social Work, 9, 174-211. 
Barth, R. P., Lee, B. R., Lindsey, M. A., Collins, F., Strieder, F., Chorpita, B. F., . . Sparks, J. A. (2012). Evidence-based practice at a crossroads: The timely emergence of common elements and common factors. Research on Social Work Practice, 22, 108-119.

Baruch, Y., \& Holton, B. C. (2008). Survey response rate levels and trends in organizational research. Human Relations, 61, 1139-1160.

Birken, S. A., Lee, S. Y., \& Weiner, B. J. (2012). Uncovering middle managers' role in healthcare innovation implementation. Implementation Science, 7, 28.

Cameron, C. A., \& Trivedi, P. K. (2009). Microeconometrics using Stata. College Station, TX: Stata Press.

Carnochan, S., Samples, M., Myers, M., \& Austin, M. J. (2013). Performance management challenges in nonprofit human service organizations. Nonprofit and Voluntary Sector Quarterly, 29.

Chagnon, F., Pouliot, L., Malo, C., Gervais, M.-J., \& Pigeon, M.-E. (2010). Comparison of determinants of research knowledge utilization by practitioners and administrators in the field of child and family social services. Implementation Science, 5, 41-53.

Claassen, J., \& Austin, M. J. (2008). Impact of organizational change on organizational culture: The prospects for introducing evidence-based practice. Journal of Evidence-Based Social Work, 5, 321-358.

Collins-Camargo, C., Sullivan, D., \& Murphy, A. (2011). Use of data to assess performance and promote outcome achievement by public and private child welfare agency staff. Children and Youth Services Review, 33, 330-339.

Doran, D., Haynes, B. R., Estabrooks, C. A., Kushniruk, A., Dubrowski, A., Bajnok, I., . . Bai, Y. Q. (2012). The role of organizational context and individual nurse characteristics in explaining variation in use of information technologies in evidence based practice. Implementation Science, 7, 122.

Epstein, I. (2010). Clinical data-mining: Integrating practice and research. New York, NY: Oxford University Press.

Gambrill, E. B. (2012). Critical thinking in clinical practice: Improving the quality of judgments and decisions (3rd ed.). New York, NY: Wiley.

Graaf, G., Carnochan, S., Radu, P. \& Austin, M. J. (2014). The impact of the Great Recession on county human service organizations: A cross-case analysis. Berkeley: Mack Center on Nonprofit and Public Sector Management in the Human Services, School of Social Welfare, University of California, Berkeley.

Gray, M., Joy, E., Plath, D., \& Webb, S. A. (2013). What supports and impedes evidence-based practice implementation? A survey of Australian social workers. British Journal of Social Work, 1-18.

Hasenfeld, Y. (2010). The attributes of human service organizations. In Y. Hasenfeld (Ed.), Human services as complex organizations (2nd ed., pp. 9-32). Thousand Oaks, CA: Sage.

Hatry, H. P. (2007). Performance measurement: Getting results (2nd ed.). Washington, DC: Urban Institute Press.

Heinrich, C. J. (2007). Evidence-based policy and performance management: Challenges and prospects in two parallel movements. American Review of Public Administration, 37, 255-277.

Heiwe, S., Kajermo, K. N., Tyni-Lenné, R., Guidetti, S., Samuelsson, M., Andersson, I. L., \& Wengström, Y. (2011). Evidence-based practice: Attitudes, knowledge and behaviour among allied health care professionals. International Journal for Quality in Health Care, 23, 198-209.

Horwitz, S. M., Hurlburt, M. S., Goldhaber-Fiebert, J. D, Palinkas, L. A., Rolls-Reutz, J., Zhang, . . Landsverk, J. (2014). Exploration and adoption of evidence-based practice by U.S. child welfare agencies. Children and Youth Services Review, 39, 149-152.

Humphries, S., Stafinski, T., Mumtaz, Z., \& Menon, D. (2014). Barriers and facilitators to evidence-use in program management: A systematic review of the literature. BMC Health Services Research, 14, 171-176.

Knight, C. (2013). Social workers' attitudes toward peer-reviewed literature: The evidence base. Journal of Teaching in Social Work, 33, 177-195.

Kroll, A. (2014). Drivers of performance information use: Systematic literature review and directions for future research. Public Performance and Management Review.

Lee, C., \& Austin, M. J. (2012). Building organizational supports for knowledge sharing in county social service agencies: Cross-case analysis of works-in-progress. Journal of Evidence-Based Social Work, 9, 3-18.

Lee, K. J., \& Carlin, J. B. (2010). Multiple imputation for missing data: Fully conditional specification versus multivariate normal imputation. American Journal of Epidemiology, 171, 624-632.

Lee, S. J., Bright, C. L., \& Berlin, L. J. (2013). Organizational influences on data use among child welfare workers. Child Welfare, 92, 97-118.

LeRoux, K., \& Wright, N. (2010). Does performance measurement improve strategic decision-making? Findings from a national survey of nonprofit social service agencies. Nonprofit and Voluntary Sector Quarterly, 39, 571-587.

Maynard, B. R. (2010). Social service organizations in the era of evidence-based practice: The learning organization as a guiding framework for bridging science to service. Journal of Social Work, 10, 301-316.

McBeath, B., \& Austin, M. J. (in press). The organizational context of research-minded practitioners: Challenges and opportunities. Research on Social Work Practice. 
McDaniel, R. R., \& Lanham, H. J. (2009). Evidence as a tool for managerial action: A complex adaptive systems view. Health Care Management Review, 34, 216-218.

Moynihan, D. P. (2008). The dynamics of performance management: Constructing information and reform. Washington DC: Georgetown University Press.

Moynihan, D. P., \& Lavertu, S. (2012). Does involvement in performance reforms encourage performance information use? Evaluating GPRA and PART. Public Administration Review, 72, 592-602.

Moynihan, D. P., \& Pandey, S. K. (2010). The big question for performance management: Why do managers use performance information? Journal of Public Administration Research and Theory, 20, 849-866.

Moynihan, D. P., Wright, B., \& Pandey, S. (2012). Setting the table: How transformational leadership fosters performance information use. Journal of Public Administration Research and Theory, 22, 143-64.

Nutley, S., Walter, I., \& Davies, H. T. O. (2003). From knowing to doing: A framework for understanding the evidence-intopractice agenda. Evaluation, 9, 125-148.

Nutley, S., Walter, I., \& Davies, H. T. O. (2007). Using evidence: How research can inform public service. Bristol, UK: Policy Press.

Palinkas, L. A., Holloway, I. W., Rice, E., Fuentes, D., Wu, Q., \& Chamberlain, P. (2011). Social networks and implementation of evidence-based practices in public youth-serving systems: A mixed methods study. Implementation Science, 6 , 113.

Parrish, D. E., \& Rubin, A. (2011). Validation of the Evidence-Based Practice Process Assessment Scale. Research on Social Work Practice, 21, 106-118.

Parrish, D. E., \& Rubin, A. (2012). Social workers' orientation to evidence-based practice: A comparison with psychologists and LMFTs. Social Work, 57, 201-210.

Patterson, F., Kerrin, M., \& Gatto-Rouissard, G. (2009). Characteristics and behaviours of innovative people in organizations. London, UK: City University, NESTA.

Rogers, E. M. (2003). Diffusion of innovations (5th ed.). New York, NY: Free Press.

Rosen, A. (1994). Knowledge use in direct practice. Social Service Review, 68, 561-577.

Rubin, A., \& Parrish, D. (2012). Comparing social worker and non-social worker outcomes: A research review. Social Work, 57, 309-320

Rycroft-Malone, J., Kitson, A., Harvey, G., McCormack, B., Seers, K., Titchen, A., \& Estabrooks, C. (2002). Ingredients for change: Revisiting a conceptual framework. Quality and Safety in Health Care, 11, 174-180.

Schon, D. (1983). The reflective practitioner: How professionals think in action. London, UK: Temple Smith.

Shaw, I., \& Faulkner, A. (2006). Practitioner evaluation at work. American Journal of Evaluation, 27, 44-63.

Sosin, M. R. (2010). Discretion in human service organizations: Traditional and institutional perspectives. In Y. Hasenfeld, Ed., Human Services as Complex Organizations (2nd ed., pp. 381-404). Los Angeles, CA: Sage.

Squires, J. E., Estabrooks, C. A. O’Rourke, H. M., Gustavsson, P., Newburn-Cook, C., \& Wallin, L. (2011). A systematic review of the psychometric properties of self-report research utilization measures used in healthcare. Implementation Science, 6, 83 .

StataCorp. (2011). Stata statistical software: Release 12. College Station, TX: StataCorp LP.

Taylor, C., \& White, S. (2006). Knowledge and reasoning in social work: Educating for humane judgment. British Journal of Social Work, 36, 937-954.

Thorsteinsson, H. S., \& Sveinsdottir, H. (2012). Readiness for and predictors of evidence-based practice of acute-care nurses: A cross-sectional postal survey. Scandinavian Journal of Caring Sciences, 1-10.

U.S. General Accountability Office. (2013). Program evaluation: Strategies for facilitate agencies' use of evaluation in program management and policymaking (GAO-13-570).

Von Hippel, P. T. (2007). Regression with missing Ys: An improved strategy for analyzing multiply imputed data. Sociological Methodology, 37, 83-117.

Wilson, G. (2011). Evidencing reflective practice in social work education: Theoretical uncertainties and practical challenges. British Journal of Social Work, 1-19.

Zahra, S. A., \& George, G. (2002). Absorptive capacity: A review, reconceptualization, and extension. Academy of Management Review, 27, 185-203. 